\title{
MITO E POLÍTICA: \\ NOTAS SOBRE O CONCEITO DE DESTINO \\ NO "JOVEM" BENJAMIN
}

Ernani CHAVES ${ }^{1}$

- RESUMO: O conceito de mito é uma das chaves para a compreensão do pensamento de Walter Benjamin. O objetivo deste texto é reconstituir a gênese deste conceito com base em suas primeiras formulações, tal como apresentadas em Destino e caráter, texto escrito em 1919. O presente artigo se divide em duas partes: na primeira, reconstituímos os argumentos de Benjamin, a partir da filiação do conceito de destino ao domínio de uma Teoria do Direito e sua necessária inserção em um modo de "temporalidade" definido pela "repetição"; a segunda parte pretende demonstrar que as posições de Benjamin estão estreitamente ligadas a uma posição também política: seu objetivo era, em nome de um anarquismo confesso, se contrapor a todos os "mitos" nacionalistas (que levaram a Alemanha à guerra) e à necessidade de "líderes", "condutores" (Führer) para o povo. Como exemplo dessa perspectiva política, nos baseamos na confrontação, sempre presente, de Benjamin com o Sionismo.

- PALAVRAS-CHAVE: Mito; destino; caráter; repetição; anarquismo; sionismo.

\section{I}

Um dos aspectos fundamentais da interpretação adorniana de Walter Benjamin, e que tem alimentado os estudos posteriores sobre o tema, é a sua insistência no lugar estratégico, central, decisivo, que a questão do mito representa na obra de Benjamin. Entretanto, sua originalidade não reside, pura e simplesmente, em apontar esse lugar central, mas em destacar, com precisão, o modo e o resultado da investigação benjaminiana: seu modo, uma espécie de mimesis positiva aos olhos de Adorno, na medida em que para vencer as forças do mito Benjamin precisa assemelhar-se a ele, vestir a sua roupagem para melhor combatê-lo (Adorno, 1990, p. 30); seu resultado, o de que Benjamin não se restringe a uma crítica do mito no sentido do Iluminismo, para denunciar nele seu conteúdo de ilusão, falsidade e erro, mas sim para "compor", como "nas boas variações musicais", o quadro de sua "reconciliação": "A reconciliação do mito é o tema da filosofia de Benjamin" (p. 15). "Reconciliação" aqui não

1. Professor do Departamento de Filosofia da Universidade Federal do Pará - UFPa - 66075-900 - Belém - PA. 
implica, evidentemente, uma espécie de retorno ao mito ou sua revalorização num plano mais elevado - e neste ponto Benjamin permanece "iluminista", afastado tanto da "idéia de uma nova mitologia" dos primeiros românticos quanto da "pura compreensão estética do mito" no Nietzsche de O Nascimento da Tragédia -, mas na "superação" do dualismo ontológico entre mito e sua reconciliação para, enfim, secularizá-lo. Tal procedimento, em seus princípios, já o dizia Adorno, supunha uma visada dialética. Assim, em que pesem os trabalhos publicados sobre o tema (Menninghaus, 1986; Janz, 1983), que caminham nas sendas abertas por Adorno, embora nem sempre de acordo com sua interpretação, a tentativa de compreender a concepção benjaminiana de mito, por revelar-se uma das chaves de acesso a um "retrato completo" do seu pensamento (Menninghaus, 1986, p. 7), impõe-se continuamente aos intérpretes. Escolhemos, como objeto de investigação nos limites deste artigo, um conceito fundamental, quando se trata da concepção benjaminiana de mito: o de "destino". Intentamos apresentá-lo, em suas linhas mais gerais, acompanhando o movimento de sua gênese, no momento decisivo de sua formulação no pensamento do assim chamado "jovem" Benjamin: em Destino e caráter, texto escrito em 1919, quando Benjamin ainda se encontrava na Suiça, e publicado em 1921. A escolha desse pequeno texto tem suas razões; nele podemos encontrar não apenas a primeira formulação mais acabada do conceito de destino, como também o início de um conjunto de reflexões que acompanharão a obra de Benjamin a partir daí: sobre as relações entre mito, direito, violência e poder (em Crítica da violência, de 1920-1); sobre as relações entre mito e verdade, diretamente acoplada à questão de uma teoria da crítica literária (no ensaio sobre As Afinidades eletivas, de Goethe, concluído em 1922 e publicado em 1924-5); sobre as diferenças essenciais entre tragédia "antiga" e "moderna", que concluem pela caracterização do "drama barroco" como "drama do destino" (em Origem do drama barroco alemão, a famosa Tese de Habilitação recusada em Frankfurt em 1925 e publicada integralmente em 1928); ou ainda, a partir de Rua de mão única e, principalmente em inúmeros fragmentos do Passagen-Werk, as relações entre capitalismo e pensamento mítico. Nossa tentativa de circunscrição dos elementos fundamentais que constituem o conceito de destino em Benjamin, com base em Destino e caráter, orienta-se num duplo sentido: primeiro, a partir das relações entre destino e práticas jurídicas, e segundo, a partir da consideração de uma "temporalidade" própria ao destino. Procuraremos mostrar que, no limite, a interrupção do destino fatídico, interrupção das "forças demoníacas", significa, necessariamente, contrapor ao tempo do mito uma outra forma de temporalidade, tal como as primeiras linhas de A vidados estudantes (1914) já indicavam (Benjamin, 1991b, p. 75). Utilizando essa via de acesso, buscamos alcançar dois objetivos "estratégicos" que se cruzam e se complementam: 1) mostrar que textos fundamentais da chamada fase da "maturidade", em que tantas vezes os conceitos de mito e destino aparecem, só são compreendidos à luz dos textos da juventude, o que não significa que não haja nenhuma cesura entre eles, mas que, do mesmo modo, não se pode reduzir os textos da "juventude" a um momento embrionário, de pouco valor teórico; 2) na contra-mão 
de Scholem, de Adorno e da maioria dos intérpretes, mostrar que a crítica do mito no "jovem" Benjamin tem também um aspecto profundamente político. ${ }^{2}$ Trata-se de chamar à discussão o seu "anarquismo messiânico", destacando, para tal, sua permanente confrontação com o sionismo.

\section{II}

O ponto de partida de Destino e caráter é a crítica da interpretação corrente desses dois conceitos, fundada na interdependência de ambos por meio de uma ligação de ordem puramente causal. Nesta perspectiva, o caráter "é descrito como causa do destino" (1991b, p. 171): de um lado, poder-se-ia conhecer o caráter de uma pessoa em todas as suas particularidades; de outro, os acontecimentos do mundo só poderiam ser conhecidos nos domínios em que se referem a esse caráter, de tal maneira que se pode afirmar com exatidão "tanto o que de cada caráter é experimentado de novo, quanto o que dele poderia ser consumado". Tanto num caso como no outro, o destino é derivado do caráter, estabelecendo-se entre eles uma arbitrária relação de causalidade, acabando por reduzir o domínio do caráter ao do ético e o do destino, ao religioso (1991b, p. 173). Benjamin considera essa relação "arbitrária", na medida em que o funcionamento do sistema de sinais (Zeichen), num caso e noutro, é bem diferente. Os sinais do caráter, por exemplo, são delimitados pelo corpo, tal como nos indica o procedimento do horóscopo; por sua vez, os sinais do destino incluem os corporais e o ultrapassam, atingindo os fenômenos da vida exterior. Daí, portanto, que toda tentativa de estabelecer entre esses dois domínios um nexo de causalidade resulta arbitrária, infrutífera, equivocada. Benjamin analisa com mais vagar - por motivos muito claros, como veremos - a conseqüência desastrosa de uma tal conexão arbitrária, no campo do destino.

De fato, atrelando-se o domínio do destino ao religioso, acaba-se por estabelecer uma outra conexão, não menos arbitrária: entre destino e culpa. Assim, torna-se usual afirmar que o destino infeliz é uma resposta de Deus ou dos deuses a dívidas religiosas, de tal modo que uma vida feliz deve ser uma "vida inocente, uma vida sem culpa, sem mácula de qualquer espécie" (1991b, p. 173-4). ${ }^{3}$ Para contrapor-se a essa concepção, num procedimento análogo a outros pensadores, Benjamin recorre aos

2. Intérpretes de todos os matizes ideológicos acabaram, em geral, seguindo de perto a interpretação de Scholem de que um interesse concreto de Benjamin por questões políticas só se deu a partir de 1924, isto é, de sua aproximação do marxismo. Assim, participam da mesma imagem do "jovem" Benjamin apolitico (cf. Scholem, 1989, p. 85, 87). Ao enfatizar a ruptura ocorrida com Einbahnstrasse, no que diz respeito aos "sentimentos (de Benjaminl em relação ao político". Adorno (1990, p. 32) acaba por justificar a posição de Scholem.

3. É importante destacar, neste momento da argumentação, o jogo que entretém Schuld (culpa) e Unschuld (inocência). Schuld, como sabemos, significa, ao mesmo tempo, culpa e divida, enquanto Unschuld, a ausência de culpa e/ou dividas, significa também inocência, ausência de mácula, inclusive a sexual, também designada por esta palavra 
gregos para mostrar que é possível pensar um outro conceito de destino: "Na formação greco-clássica da idéia de destino, a felicidade que cabe a uma pessoa não é compreendida, em hipótese alguma, com a confirmação de sua vida inocente, mas com a experimentação do endividamento mais pesado, o da hybris. Assim, não se encontra no destino nenhuma relação à inocência" (1991b, p. 174). ${ }^{4}$ Descartada a idéia de uma ligação natural, causal, entre destino e infelicidade, isso não quer dizer que o seu contrário seja verdadeiro. A argumentação de Benjamin - e nisso consiste, a nosso ver, seu traço mais característico - caminha justamente para demonstrar que à esfera do destino não pertence nem a idéia de infelicidade (e para isso serviu a referência aos gregos), nem as de felicidade (Glück) e bem-aventurança (Seligkeit), como o querem os "modernos". Ao contrário, afirma Benjamin, "a felicidade é, muito mais, aquilo que arranca os felizes da estreita ligação (Verkettung) ao destino e à teia do próprio destino" (idem).

Afastando-se tanto da concepção que atribui aos gregos, que separa vida feliz e inocência, quanto da concepção "moderna", que une destino à infelicidade e à culpa, enraizando de vez a questão do destino no domínio do religioso, Benjamin avança sua tese de que essa outra ordem, em que de fato se deve buscar o domínio que é próprio ao destino, supõe uma outra "balança", na qual "bem-aventurança e inocência ficaram tão leves, que evaporaram": a "balança" do direito. Em oposição ao reino da justiça (Gerechtigkeit), a ordem do direito (Recht) é o terreno fértil onde podem brotar as sementes da culpa e da infelicidade. Assim, se hoje consideramos que o destino pertence ao domínio do religioso é porque, no decorrer da história, houve uma inversão de tal monta que os homens "confundiram" direito com justiça, aquele mascarando-se com esta, conduzindo a humanidade a se enredar cada vez mais nas teias da fatalidade:

Equivocadamente, por causa de sua troca enganosa com o reino da justiça, a ordem do direito, que é apenas um residuo do plano demoniaco da existência humana, determinou não apenas suas [a dos homens] relações com as normas jurídicas, mas também com os deuses, conservou-se para além do tempo em que se inaugurou a vitória sobre os demônios. (1991b, p. 174)

A posição de Benjamin, está enfim, mais clara: pode parecer, à primeira vista, que sua crítica da ligação que se estabeleceu entre destino e religião desembocou numa valorização do destino. Nada mais distante de Benjamin que tal idéia. O que ele pretendia, de fato, ao desligar destino e religião, era indicar o campo específico do destino, definido na relação entre culpa e inocência, felicidade e infelicidade: 0 campo do direito. Sua crítica do direito, portanto, atinge dois alvos ao mesmo tempo: ela serve tanto para desmascarar a "troca enganosa" que nos faz confundir direito e

4. A problemática das relações entre destino e felicidade delimita, de certo modo, o interesse pela filosofia grega e a sua presença no "jovem" Benjamin. Em um texto de 1916, "A felicidade do homem antigo", que com o "Sócrates" da mesma época é uma das primeiras demonstrações explícitas desse interesse, Benjamin, na esteira da distinção de Schiller entre o "ingênuo" e o "sentimental", já criticava o conceito "moderno" de felicidade. Entretanto, à diferença de Destino e caráter, a felicidade para os antigos é vista como um misto de "vitória e festa, mérito e inocência (Unschuld)" (Benjamin, 1991b, p. 128). 
justiça, quanto nossa crença de que o direito é uma elevada elaboração racional, uma conquista inelutável da "civilização", que nele nada mais há de mítico, que o direito, enfim, venceu a "luta contra os demônios". Uma teoria do direito só pode fundar-se, segundo Benjamin, na conexão necessária que se estabelece entre a ação do destino, o aparecimento da culpa e a sua indispensável expiação. Uma tal conexão não é "arbitrária" - tal como a que se efetua entre destino e domínio do religioso - nem exterior, como uma espécie posterior de aplicação de um esquema a outro, mas o conceito de direito, desde sua origem, é tributário do desenvolvimento dos conceitos de destino, culpa e expiação (Menninghaus, 1982, p. 99). Entretanto, a ordem do direito nos engana na medida em que a supomos capaz de "vencer os demônios". Ao contrário, como Benjamin o diz, o direito "é apenas um resíduo do plano demoníaco da existência humana". Não é o domínio do direito, portanto, que pode, historicamente, servir de exemplo para demonstrar a vitória da humanidade "contra os demônios", contra as forças do mito, mas a tragédia grega. Nesta, "a cabeça do gênio se elevou, pela primeira vez, das névoas da culpa" (Benjamin, 1991b, p. 174).

A referência à tragédia grega nos situa, definitivamente, no cerne da concepção benjaminiana de destino. Benjamin subverte o esquema explicativo mais clássico da tragédia, qual seja, o de que o herói postado diante do seu destino luta contra ele para, enfim, sucumbir às suas forças; no limite, sucumbir à própria culpa. Em oposição a esse esquema, Benjamin entende a tragédia como a interrupção do fluxo inexorável do destino, sem que isso venha a significar uma espécie de retorno à pureza do homem, uma libertação da culpa e da expiação ou ainda uma reconciliação com Deus. Afastando-se de Hegel neste ponto, Benjamin nega toda tentativa de restabelecimento da "ordem ética do mundo" como a promessa cumprida na tragédia. ${ }^{5} \mathrm{Se}-\mathrm{e}$ agora de acordo com Hegel - a esfera da lei e do direito é, para Benjamin, essencialmente estranha à "moralidade substancial" da vida heróica na epopéia e na tragédia, ele não reconhece - como Hegel - que o direito seja o reino da liberdade realizada (1986b, p. 196), insistindo, como vimos, no pertencimento íntimo entre direito e destino. Embora Hegel não deixe de notar que "violência e tirania podem ser um elemento do direito positivo" (1986b, p. 34-5), remete este fenônemo do mundo empírico ao mundo do acaso, que não pertence à natureza do direito. Na perspectiva de Benjamin, ao contrário, direito e violência são irmãos siameses. Por isso, a tragédia não poderia visar a nenhuma espécie de reconciliação ética. Antes, ela vive da tentativa feita pelo homem moral "ainda mudo, ainda menor", de se elevar "no estremecimento deste mundo doloroso". O herói surge, justamente, desse "paradoxo": "o paradoxo do nascimento do gênio na mudez moral, a infantilidade moral é o sublime da tragédia"

\footnotetext{
5. "Em geral, podemos dizer que o tema da tragédia, na sua origem, é o divino; mas não o divino concebido no conteúdo cla consciência religiosa, mas como aquilo que, no mundo, se realiza na ação individual, sem perder nestarealização seu caráter substancial e sem se ver mudado no seu oposto. Nessa forma, a substância do querer e do realizar é o ético. Pois o ético, se nós o compreendermos na sua solidez imediatizável e não apenas a partir da reflexão subjetiva, como o moralmente formal, é a divindade na sua realidade no mundo, o substancial..."(Hegel, 1986a, p. 522)
} 
(Benjamin, p. 175). ${ }^{6}$ Nem inocente, nem culpado (daí sua "infantilidade moral"), o homem profano se reconhece, na tragédia, como "melhor que os seus deuses". Ora, a ordem do direito é, em todos os aspectos, a contraposição da experiência do "trágico", pois sua condenação não visa, prioritariamente, condenar para a aplicação da pena, mas sim para a produção da culpa. O destino, neste diapasão, é definido como "a relação de culpa dos seres vivos" (1991b, p. 175). ${ }^{7}$ Sua lógica é a do mito, isto é, a lógica que considera a vida como uma condenação, que a vida, antes de mais nada, é condenação para, em seguida, tornar-se culpa (1991b, p. 175). Afastando sua concepção de destino do "reino vegetal", Benjamin quer fazer a sua "assinalação histórica", quer mostrar como a "lógica do mito" pode ser desmascarada pela sua inserção "histórico-filosófica".

O direito aparece, portanto, como a perpetuação da ordem mítica nas sociedades que pensavam tê-la eliminado. O juiz pode encontrar em todos os atos humanos a ação inexorável do destino; o processo de julgamento penal descreve no seu termo não mais um homem, mas um "homem puro e simples", uma "vida simples", "natural", vida entre outras vidas, determinada na sua "aparência" pela sua participação "natural" no universo da "culpa" e da "infelicidade" (1991b, p. 175). É justamente essa "naturalização" da culpa que torna o direito um "resíduo do plano demoníaco da existência humana". Só uma operação de ordem "filósofico-histórica", tal como Benjamin busca empreender, poderia nos libertar dessa "troca enganosa". Como vemos, longe de repetir a argumentação iluminista, Benjamin começa a escrever a "Dialética do esclarecimento".

Após delimitar o domínio do destino na ordem do direito, Benjamin introduz um segundo aspecto de sua concepção de destino: o de sua "temporalidade". Para isso, recorre ao exemplo da prática dos videntes. Inicialmente, a "vidente" (a weise Frau, literalmente "a mulher sábia") age de modo análogo ao procedimento judiciário, na medida em que acopla a vida humana às cartas e aos planetas, introduzindo-a no "conjunto das relações que fazem do homem um culpado", pela "simples técnica" de, por meio de sinais, encontrar no homem uma "vida natural", conectada com os astros e o cosmos, fazendo parte de seu movimento. Do mesmo modo, aquele que consulta a vidente abdica de qualquer outro tipo de vida em favor daquilo que a torna culpabilizada. O argumento utilizado em relação ao direito torna a se repetir: é a

6. Neste aspecto, Benjamin não está distante de Hegel, para quem "os heróis trágicos são tão culpados quanto inocentes", nascendo dai a "força do seu grande caráter" (cf. Hegel, 1986a, p. 545-6).

7. Esta mesma definição nos remete a As Afinidades Eletivas de Goethe, no contexto de crítica ao livro de Gundolf (eminente representante do "Círculo de Stefan George") sobre Goethe: "Essa espécie de existência submetida a um destino, que encerra em um único conjunto os seres vivos compostos de culpa e expiação, é aquilo que é desenvolvido pelo poeta nesta obra. Não há que compará-la, como sustenta Gundolf, com o desabrochar de uma existência vegetal. Não é possivel pensar em nada que lhe seja mais contraposto. Não: não há que 'interpretar a idéia de caráter e destino nas Afinidades Eletivas por analogia às relações entre semente, flor e fruto, estabelecidas como lei por Goethe'. Isso não é possivel, nem em Goethe nem em ninguém que preste atenção à questão. Pois o destino é algo que não afeta as inocentes plantas (à diferença dos personagens do relato). O destino é a relação de culpa entre seres vivos" (Benjamin, 1991a, p. 33). 
"culpa" que introduz o homem no conjunto dos seres vivos, fazendo com que sua vida seja reduzida ao "natural", à semelhança do movimento dos astros e dos planetas. Benjamin entende que esse movimento de culpabilização "naturalizadora" constitui uma certa figura temporal, bem diferente de outras temporalidades, seja a da salvação, a da música ou mesmo a da verdade (1991b, p. 176). O modus operandi da temporalidade própria ao destino nos é "ensinado" pelas cartomantes e quiromantes. A esse tempo, Benjamin chama de "parasitário" (1991b, p. 176).

O que significa dizer que o tempo do destino é "parasitário"? Em primeiro lugar, que esse tempo não conhece o "presente", pois pode, a qualquer momento, ser igualado a umoutro tempo que já passou. Em segundo lugar, que não é autônomo, que "parasita" um outro tempo, o tempo de uma "vida superior", que é muito pouco "natural". Enfim, na medida em que não conhece o "presente", estão eliminados os "momentos fatídicos" (a não ser nos "péssimos romances", afirma Benjamin), podendo-se conhecer do passado e do futuro apenas algumas de suas "variações particulares".

Definindo o tempo do destino - e, por conseguinte, o do mito - como "parasitário", Benjamin dá continuidade às reflexões iniciadas em $A$ vida dos estudantes - e cuja formulação mais importante, até Destino e caráter, aparece em Drama barroco e tragédia, outro pequeno texto de 1916, onde germinam as primeiras idéias que, futuramente, serão desenvolvidas na Tese de Habilitação; neste texto, Benjamin se empenha em distinguir diferentes níveis de temporalidade: a "mecânica", cuja imagem preferencial já é a dos "ponteiros do relógio", tempo "homogêneo e vazio", como dirá muitos anos depois nas Teses "Sobre o conceito de História", que não diz respeito a nenhum acontecimento empírico particular; a temporalidade propriamente histórica, essencialmente "finita", que exige seu termo, sua interrupção, confundindo-se nesse ponto com a temporalidade "messiânica"; a temporalidade do "trágico" que, à diferença da temporalidade histórica, não diz respeito ao universal, ao geral, ao que é comum à humanidade, mas sim ao individual, ao tempo que é próprio do "herói" e não de todos, mas que, à semelhança do tempo histórico, exige também seu acabamento, sua interrupção, relacionando-se, do mesmo modo, ao tempo "messiânico". Dessa maneira, construindo uma espécie de "fenomenologia do tempo" (Menninghaus, 1982, p. 146, nota 16). Benjamin desde seus primeiros escritos procura afastar-se tanto de uma concepção de tempo objetivo, que o considera mera sucessão de eventos pontuais, interiores e exteriores, como também de uma concepção dirigida pelas regras definidas pelo "formalismo das condições kantianas a prion" (Tiedemann, 1987, p. 95). Neste quadro, "Destino e caráter" introduz mais uma possibilidade de se conceber a temporalidade com base no conceito de destino: a temporalidade própria do mito. Podendo tornar-se igual a um tempo que já passou, a temporalidade do destino é a da "repetição" ou, como Benjamin dirá tanto no ensaio sobre As Afinidades eletivas, quanto no Origem do drama barroco alemão ou ainda em um fragmento do Passagen-Werk, o tempo do "Eterno Retorno" (Benjamin, 1991a, p. 137, 313; 1991c, p. 178); dependendo de um outro tempo, "tempo de uma vida superior" (da divindade e dos seres mitológicos em geral), o tempo do destino não pode alcançar seu termo, 
não pode tornar-se messiânico, pois está voltado à infinita repetição; desconhecendo o "presente" (pois o presente "já foi"), impede o gesto heróico, o momento da decisão ou da passividade, o momento do silêncio em que o herói, "paradoxalmente", ao assumir a sua "culpa", liberta-se dela; do mesmo modo, pela repetição infinita que o caracteriza, o tempo do destino pouco ou nada sabe do passado (pois ele é "igual" ao que vem depois) e pouco ou nada pode dizer do futuro (pois a "predição" é também repetição, reiteração do que já passou). Desse modo, sua não-autonomia como sinônimo de "repetição" interdita ao tempo do destino toda espécie de consideração acerca da liberdade e autodeterminação possíveis aos indivíduos. Aos que se deixam reger por ele, longe está a conquista da "maioridade".

Benjamin afirma que a comprovação dessa idéia de "tempo parasitário" vem do trabalho das cartomantes e quiromantes. São elas que consideram a vida humana regida por outras determinações, que não as impostas pela própria liberdade e autonomia do sujeito. Entretanto, cartomantes e quiromantes possuem uma ambigüidade que o direito não tem: de início, Benjamin as iguala à ordem do direito, na medida em que introduzem o homem no mundo da culpa; entretanto, diferenciam-se do direito num aspecto fundamental aos olhos de Benjamin: do mesmo modo que a tragédia grega, mas por outras vias certamente, as práticas da vidência fundam uma noção de destino totalmente desvinculada da de caráter, não estabelecendo entre ambas nenhuma relação de "causalidade"; além desse aspecto, existe um outro que faz Benjamin valorizar positivamente as práticas da vidência: é que estas são vistas como uma "prática interpretativa" entre outras. Do primeiro ponto de vista - isto é, o das relações entre destino e caráter - as práticas da vidência, por assumirem integralmente como pressuposto o caráter "natural" da vida do homem, acabam por aproximarem-se da tragédia, já que, ao desvincular os dois termos, destino e caráter, de sua conotação religiosa e moral, podem também afirmar que somos todos "culpados e inocentes". Deste ponto de vista, o que Benjamin está valorizando na prática da vidência, em detrimento da prática jurídica, não é nem o que haveria de "irracional" ou "intuitivo" na primeira, em oposição à lógica do direito, mas o fato de este não reconhecer como seu pressuposto básico a consideração da vida "natural", abrigando-se, indevidamente, sob uma "vestimenta" que não lhe cabe. Assim, a ligação que a prática da vidência acaba realizando entre destino e caráter não aparece como "arbitrária", falsa ou inapropriada para Benjamin, por se reconhecer ancorada na "vida natural", por não "se vestir" com o ético ou o religioso. Considerando o outro ponto de vista - isto é, o da relação entre práticas de vidência e práticas de interpretação -, se Benjamin, na época, declarou que "Uma filosofia que não inclui a possibilidade do vaticínio pela borra de café e não pode explicá-la, não pode ser uma verdadeira filosofia (Scholem, 1989, p. 68), ${ }^{8}$ tais palavras não podem ser entendidas como um elogio desmesurado,

8. Questão que se constituiu como o cerne da interpretação de As afinidades eletivas, quando Benjamin, na contra-mão dos intérpretes, não reconhece na justificação do "matrimônio" (um dos pilares do direito burguês) 0 tema do livro. Ao contrário, escreve: "O mítico é o tema deste livro: o relato aparece como um jogo de sombras mítico sob as vestimentas da época de Goethe" (1991a, p. 140). Ora, esse "jogo de sombras mitico" se manifesta, 
acrítico, às práticas da vidência, mas como uma reiteração de sua importância - assim como de todo o conjunto das disciplinas mânticas -, enquanto uma "prática interpretativa" que poderia reintroduzir na filosofia, tal como o Programa de uma Filosofia por vir o enunciava, a dimensão da Lehre (doutrina) enquanto "ensinamento", "sabedoria", "instrução", no seu significado original na Tora hebraica, considerando teologia e filosofia não mais como campos antagônicos. Não se trata, portanto, como uma leitura demasiado rápida pode sugerir, da formulação de que filósofo e vidente se igualam do ponto de vista do conteúdo da reflexão, mas que o filósofo "por vir" deve prestar atenção em práticas que, exteriores ao discurso filósofico, podem contribuir para subverter a direção que historicamente lhe foi dada. Daí a crítica dirigida, no texto anteriormente referido, à insuficiência do conceito kantiano de "experiência", assim como, anos depois, no "Prefácio" ao Origem do drama barroco alemão à supremacia do "sistema", ambos julgados insuficientes para formular corretamente os problemas de nossa época. Como Scholem bem observa, é dentro desta perspectiva que também devemos ler os textos sobre o haxixe (1989, p. 68). ${ }^{9}$

Voltando a Destino e caráter, já se pode ver que também nele as "práticas da vidência" aparecem no interior da "Dialética - benjaminiana - do esclarecimento". Isso quer dizer que práticas mânticas, o "esoterismo" em geral, não são por si só uma vantagem, um procedimento e uma prática alternativa a uma reflexão acorrentada à razão. Lembremos apenas que, em Origem do Drama barroco alemão, Benjamin deplora a debilidade da filosofia "derivada do seu contato com o esoterismo": uma confiança quase cega na "visão", explicitamente referida às doutrinas neo-platônicas do paganismo e à "intuição", tal como concebida pela fenomenologia de sua época (Benjamin, 1991a, p. 215).

Com essas considerações, fechamos o círculo da argumentação de Benjamin nesta primeira formulação do conceito de destino. Como vimos, criticar sua tradução no religioso implica remeter o destino para onde não parece existir nenhum vestígio seu: uma teoria do direito. Investigar sua eficácia, por sua vez, supõe desenhar os contornos da temporalidade que lhe é própria. Num caso e noutro, Benjamin realiza a sua assinalação histórico-filosófica.

\section{III}

Não é ocasional que Destino e caráter desenvolva semelhantes idéias. Podemos dizer que 1919, quando este texto foi escrito, é um ano extremamente importante na

segundo a análise de Benjamin, principalmente nos elementos "naturais" presentes na obra de Goethe. A esses elementos da "natureza", em Origem do drama barroco alemão, Benjamin acrescenta os "adereços fatídicos", os "objetivos" que criam vida e investem contra o mundo humano.

9. Apenas chamamos a atenção para o fato de que o argumento de Scholem, neste caso, visa, também, "eliminar" da biografia de Benjamin a idéia de que seu interesse pelas drogas seja visto como "pessoal", movido pelo vício e não puramente "teórico". 
vida de Benjamin. Sua permanência na Suíça - onde chegou em julho de 1917, permanecendo até novembro de 1920 - primeiro em Zurique, depois em Berna e Muri, se insere num quadro mais geral que é o da eclosão da Primeira Guerra. Benjamin era, assim, um dos inúmeros refugiados - uma conjunção de várias nacionalidades e diversos matizes ideológicos, espalhados nas grandes cidades suíças - que procuravam com a neutralidade suiça expressar seu protesto "pacificista". Durante esse ano, Scholem reside "a dois minutos" dele e de Dora, o que significa intermináveis discussões sobre teologia e mística, além da leitura, por exemplo, do livro de Hermann Cohen sobre o conceito de experiência em Kant; no início do ano conhece Hugo Ball e logo depois, por intermédio dele, Ernst Bloch. Em junho, defende sua tese de doutorado na Universidade de Berna. Apesar de ter presenciado suas longas conversas e discussões com Ball e Bloch, Scholem insiste em reafirmar o pouco interesse de Benjamin pela política. Entretanto, como ele mesmo o testemunha, é por intermédio de Bloch que Benjamin entra em contato com o livro de Sorel, Réflexions sur la violence (Scholem, 1989, p. 92). ${ }^{10}$ Ora, longe de amenidades ou coisas do gênero, as conversas entre esses três homens giravam também em torno de política. Poderíamos dizer que a obra de Sorel e seu "anarco-sindicalismo" era um ponto comum de interesse entre eles. Sorel, de fato, vinha reforçar o "anarquismo" que o próprio Benjamin atribuía a si mesmo. O impacto das Réflexions pode ser medido não só por Benjamin ter dedicado a ele o ensaio "Crítica da violência", de 1921, como também pela repercussão em toda a sua obra posterior (Kambas, 1992). Por outro lado, como negar um interesse pela política, se o próprio Benjamin planejava escrever uma série de textos que, justamente, tinham a política como tema? De fato, em carta a Scholem, datada aproximadamente de 1.12.1920, ele expunha sua "trilogia" sobre política: uma crítica filosófica de Lesabéndio, o romance fantástico de Paul Scheerbart, intitulada "Der wahre Politiker" (infelizmente perdido), que deveria valer como uma crítica do "ativismo infantil" de Kurt Hiller, velho adversário desde os tempos do Movimento de Juventude; uma "Dissolução da Violência" (provavelmente absorvido em Crítica da Violência) e "Teleologia sem meta final", provavelmente jamais escrito . Estes dois últimos textos teriam um título comum: "Die wahre Politik" (Benjamin, p. 223, 235, 237, 247). ${ }^{11}$

Esse "anarquismo" confesso, cujos traços a crítica do direito em Destino e caráter deixa entrever, faz parte, como o indicou Löwy (1983), de uma atitude comum a um conjunto de intelectuais judeus, inconformados com os rumos tomados pela socialdemocracia e que, por isso, enveredaram por posições anarquistas. Nessa perspectiva, a crítica do Estado e sua intromissão na cultura, a crítica da Universidade, que transformou ciência e pesquisa em profissão e ganha-pão, a crítica da instituição

10. Cf. carta a Scholem, de 29.5.1926. In: Benjamin, 1978, p. 426

11. Contra Hiller, por exemplo, diz ter escrito um trabalho intitulado "Não existe nenhum trabalho intelectual" (Benjamin, 1978, p. 235), que se perdeu. Em 17.4.1920, anuncia a Scholem que escreveu o pequeno texto "Vida e Violência" (Benjamin, 1978, p. 237; Benjamin, 1991d, p. 104-8). Sobre Lesabéndio, Benjamin escreveu mais dois textos (cf. 1991a, p. 618-20 e 630-2). O segundo texto, o que se perdeu, foi escrito em Lugano, na mesma época de Destino e caráter. 
familiar e do casamento como meta necessária a ser alcançada pelo jovem, tal como aparecem em $A$ vida dos estudantes, já conteriam claros sintomas desse "anarquismo" que, segundo Löwy, deitaria suas raízes, em última instância, no "anticapitalismo romântico". "Anarquismo messiânico", bem entendido, porque suporia a existência de um paraíso perdido a ser reencontrado, tal como as "imagens utópicas" do reino messiânico ou da Revolução Francesa evocadas naquele texto. ${ }^{12}$ Do mesmo modo, Löwy destaca as leituras feitas por Benjamin de Gustav Landauer, Strindberg, Nietzsche e a admiração por Tolstói, nomes estritamente vinculados, no começo do século, às posições dos anarquistas.

Gostaríamos de nos deter na discussão de Benjamin com o sionismo, na medida em que ela está diretamente relacionada, a nosso ver, com a sua posição crítica diante do mito. Vindo de uma família abastada e assimilada, somente em 1912, quando conhece o escritor e sionista Ludwig Strauss é que Benjamin se vê diretamente confrontado com a sua "identidade judaica" e com o problema do sionismo. ${ }^{13} \mathrm{Se}$ podemos dizer que ele se reconcilia com sua "identidade judaica", o mesmo não se pode dizer de sua posição diante do sionismo:

Gostaria de dizer uma palavra sobre o Sionismo [escreve ele a Strauss] ... Não encontrei principios como os seus no trabalho judaico de nenhum sionista que conheci. Não achei que os sionistas tornaram a sua vida judaica, que tinham mais do que vagas representações do espírito judaico. O judaico era seu impulso natural, o sionismo, coisa de organizações políticas. Sua personalidade não era determinada interiormente, de modo algum, pelo judaico: propagam a Palestina e bebem como alemães. (Benjamin, 1991b, p. 838)

Na mesma carta, distinguia entre três tipos de Sionismo: o palestino, considerado uma "necessidade natural"; o alemão, que primava pela "imperfeição"; e o sionismo cultural, "que enxerga valores judaicos por toda parte e trabalha por eles". É a esse último tipo que Benjamin diz se sentir filiado. Na verdade, ele critica o sionismo alemão por desconhecer a idéia de "cosmopolitismo", em tudo oposta ao "nacionalismo" cultivado por seus militantes e que ele, algumas vezes, com mordacidade cruel, chamava de "sionismo agrário", referindo-se a uma espécie de recrutamento de trabalhadores e de militantes para seguirem para a Palestina, a fim de trabalhar na agricultura. Segundo o testemunho de Scholem, na opinião de Benjamin o sionismo deveria se livrar de três coisas: "a orientação agrícola, a ideologia racial e os argumentos de Buber sobre sangue e experiência" (Scholem, 1989, p. 38).

É o nome de Martin Buber que estabelecerá a ligação entre anarquismo, sionismo e crítica do mito. De fato, Benjamin conclui Destino e caráter com a constatação de

12. Se se pode discordar do parti pris da interpretação de Löwy, ou seja, sua "leitura demasiado cronológica" do conceito benjaminiano de origem (Ursprung) (cf. Gagnebin, 1989), não se pode negar a importância e a pertinência de muitas de suas análises históricas. Suas pesquisas acerca do milieu judaico no começo do século têm se mostrado fundamentais para a reconstituição do Zeitgeist, em que o pensamento de Benjamin se enraíza. Seus inúmeros paradoxos ganham uma explicação.

13. A correspondência com Strauss, que documenta esse primeiro embate, se encontra em Benjamin, 1991b. 
que o direito é uma "troca enganosa", enquanto o herói trágico, por sua vez, representava o momento na história da humanidade em que o homem venceu as "forças demoníacas". Expressão "moderna" do pensamento mítico, o direito reencena o "drama do destino", conjugando em seus procedimentos e ordenamentos, culpa, pecado e expiação. Por que no direito e não, por exemplo, na religião? É que religião e conhecimento histórico-filosófico têm, no presente, a função de fazer a assinalação histórica do mito e assim, vencer as "forças demoníacas". Religião e conhecimento histórico-filosófico representam o papel antes desempenhado pelo herói trágico. A posição que Benjamin defende em relação à religião é, neste momento, a de Hermann Cohen. Admirador, ouvinte das aulas de Cohen em Berlim e atento leitor de seus livros, Benjamin, seguindo Cohen, concebe as religiões monoteístas da revelação como opostas ao mito, como tentativas de libertar a religião das amarras do mito (Cohen, apud Menninghaus, 1986, p. 20). Scholem formulou assim essa questão:

O impulso religioso original inerente ao judaismo, que encontrou sua expressão válida no monoteísmo ético dos Profetas de Israel e sua formulação conceitual na filosofia judaica da religião durante a Idade Média, sempre se caracterizou como uma reação contra a mitologia. Em oposição à unidade panteista, no mito, de Deus, cosmo e homem, e em oposição aos mitos da natureza das religiões do Oriente Próximo, o judaísmo visava uma separação radical desses três domínios; e, acima de tudo, considerou fundamentalmente intransponivel o abismo entre Criador e Sua criatura. O culto judaico implicava renúncia, ou mesmo rejeição polêmica, das imagens e símbolos nos quais o mundo mítico encontrava expressão. O judaísmo empenhou-se em desbravar uma área, a da revelação monoteista, da qual a mitologia ficaria excluida. Aqueles vestígios de mito que foram aqui e acolá preservados, viram-se despojados da sua força simbólica primitiva, sendo tomados num sentido puramente metafórico. (1988, p. 106-7)

O que está em questão aqui, nesta rejeição do mito, é o problema teológico do mal, que acaba por demarcar os limites entre a perspectiva filosófica e a mística. É que para o judaísmo "racional" (a expressão é de Scholem), solidificado na Idade Média e que encontra em Cohen um representante emérito, o problema do mal não tem importância em si mesmo. A preocupação maior era com a "pureza" de Deus, cuja preservação dependia, em primeiro lugar, da luta contra o mito e as representações antropomórficas. Para Cohen (apud Scholem, 1972, p. 35): "O Mal é inexistente ... Um poder do Mal só existe no mito". Em oposição aos "filósofos" do judaísmo "racional", os cabalistas consideravam que o problema do Mal deveria ser enfrentado e não descartado para os confins do pensamento mítico.

Adotando a posição de Cohen e da tradição do judaísmo "racional" (o que quer dizer que nem sempre Benjamin tomou o partido da "mística", aspecto sempre enfatizado pelos intérpretes), Benjamin se alinhava contra Martin Buber, um dos grandes líderes do movimento sionista. Suas relações com Buber sempre foram tensas e Benjamin muito reticente a todas as tentativas de aproximação, embora tivesse mantido com ele um permanente diálogo (O Diário de Moscou, por exemplo, foi publicado na Die Kreatur, revista dirigida por Buber, embora Benjamin sempre tivesse recusado ser colaborador permanente da revista Die Jude, também dirigida por Buber). 
Mas, de acordo com Scholem, Buber, seguindo uma "forte inspiração nietzscheana", acredita que "a predisposição mítica é característica dos judeus desde as origens". Segundo Ze'ev Lewy, a dicotomia "contra ou a favor do mito caracterizou o pensamento judaico (principalmente no círculo cultural alemão) nas primeiras décadas deste século" (1988, p. 988). Assim, poder-se-ia dividir as facções em três grupos: 1) a de Cohen, para quem "mito e essência do judaísmo eram, fundamentalmente, opostos um ao outro"; 2) a de David Neumarks, para quem o mito fora apenas uma etapa no desenvolvimento do monoteísmo judaico, um "modo de interpretação primitivo", substituído por uma "amadurecida visão religiosa"; 3) a de Buber e Franz Rosenzweig, fortes críticos de todas as tendências que desvalorizavam o mito. Buber, por exemplo, considerava "positiva a relação com os elementos mitológicos do judaísmo" (1988, p. 992).

Certamente este não é o lugar para se examinar de perto se as críticas de Benjamin a Buber são procedentes, se o sionismo tal como Benjamin o critica é o mesmo professado por Buber. Cabe tão-somente ressaltar que o alvo mais imediato de Benjamin, o que leva uma posição crítica radical em relação a Buber, é a implicação entre "rejuvenescimento do judaísmo", e "retomada dos elementos mitológicos do judaísmo", que se encontra no cerne da obra de Buber. Segundo Anatol Rosenfeld, a "vivência mítica" significa para Buber a possibilidade de

arrancar o fato ou objeto do contexto causal e do tecido das mediações empiricas, apreendendo-os com toda a paixão da alma na sua concretude singular e relacionando-os, em vez de com causas e efeitos, com seu próprio conteúdo e significado, como manifestações do mundo inefável. (1993, p. 92)

\section{Vejamos o próprio Buber: é dessa "vivência mítica" que}

resulta a intuição empírica inadequada do homem primitivo ... mas, por outro lado, seu sentimento exaltado em face do Irracional na experiência particular e em face do que nela não pode ser entendido à base de outros eventos, mas que somente pode ser apreendido em si mesmo como simbolo de um contexto secreto, supracausal, com o signo intangivel do absoluto. Ele instaura tais eventos no mundo do divino: ele os mitiza. (Buber apud Rosenfeld, 1993, p. 92)

Buber vê presente essa tendência à mitificação não apenas no homem primitivo, mas até nas sociedades ditas "civilizadas", surgindo em "tempos de grande tensão e intensidade de experiência" (Buber falava do seu próprio tempo, sem dúvida!), que produzem no homem uma desconfiança em relação à cadeia de "causalidade" com que os fatos eram explicados, ascendendo para algo significativo "além da causalidade", abrindo, portanto, o caminho para o Mito:

Mesmo hoje, qualquer homem verdadeiramente vivo encontra-se numa relação semelhante em face do homem que considera seu herói. Podendo embora inseri-lo na cadeia causal, tende a mitizá-lo porque a contemplação mítica abre uma verdade mais profunda e plena que qualquer consideração de ordem causal. Assim, o mito é uma função eterna da alma. (p. 92-3) 
Ora, como vimos, a crítica benjaminiana à "cadeia da causalidade" segue em direção claramente oposta: não se trata de "redescobrir" a potência das forças míticas, mas de demonstrar, com sua assinalação histórico-filosófica, a imbricação entre "cadeia de causalidade" e "forças míticas."

Neste diapasão, a idéia de um "mito judaico" só poderia aparecer como extremamente problemática para Benjamin, como tributária da idéia de um "destino" do povo judeu, destino esse com o qual sionistas e anti-semitas concordavam plenamente: a realização completa do povo judeu e de sua cultura não poderia se dar em uma terra não-judaica. Com isso, queremos dizer que o fato de Benjamin não ter seguido para a Palestina para trabalhar na Universidade de Jerusalém, no final dos anos 30, como era desejo de Scholem e como o próprio Benjamin havia se comprometido formalmente a fazer, não se deve apenas à paixão por Asja Lacis ou pelas suas inclinações marxistas, mas por uma desconfiança enraízada em relação à idéia do retorno à "terra prometida". Podemos dizer que é essa mesma crítica do "mito judaico" que norteia sua crítica da interpretação de Kafka, já nos anos 30, feita por Max Brod, como vemos em carta a Scholem, de 12 de junho de 1938: "O 'significado ao mesmo tempo realista-judaico' do 'Castelo' oculta os traços repelidos e aterrorizantes com os quais o mundo superior em Kafka é equipado, que já deveria ser suspeito aos sionistas, em prol de uma interpretação edificante".

Pode-se, portanto, encontrar na crítica benjaminiana do mito, tal como é formulada nessa época, um direcionamento político preciso. A crítica do sionismo "oficial" (não esqueçamos, entretanto, que Benjamin não identifica sionismo e judaísmo, ou seja, o sionismo não poderia erigir-se em porta-voz da "cultura judaica") se entrelaça à crítica de todos os outros "mitos" que povoavam a Europa e que levaram a Alemanha à guerra, com o apoio entusiasmado e extasiado da população: o nacionalismo exacerbado e a necessidade de um "Führer", um "condutor", perigos que nem os sionistas, nem os social-democratas conseguiram exorcizar. A crítica do mito implicava, portanto, no plano imediato, a rejeição dos emblemas justificadores da guerra, e, no plano mediato, reflexivo, uma concepção de crítica fundada numa filosofia da história. Crítica do mito, concebido como sinônimo de subserviência ao "destino" e crítica dos movimentos políticos "mitificadores" caminhavam de par. O "jovem" Benjamin, pretensamente apolítico, abria caminho em direção ao "materialismo". Em 1921, inspirado em Weber, mas ao mesmo tempo distante dele, escrevia "Capitalismo como religião", em que fazia uma crítica do Capitalismo a partir da sua consideração como uma espécie de "religião da culpa" elevada ao extremo máximo: "O Capitalismo - como deve ser provado não apenas no Calvinismo, mas também nas demais orientações cristãs ortodoxas - se desenvolveu, de forma parasitária, do Cristianismo no Ocidente, de tal maneira que, por último e no essencial, a história do Cristianismo é a história do seu parasita, o Capitalismo" (Benjamin, 1991d, p. 102). A relação entre capitalismo e "forças míticas" se fortalecerá a partir de Rua de mão única, de tal maneira que a consideração de um contém, necessariamente, o outro: "O Capitalismo foi um fenômeno natural, com o qual chegou um sono de sonhos na 
Europa e nele uma reativação das forças míticas" (1991c, p. 494). Contra essa reativação, a idéia de "revolução" como interrupção messiânica, a idéia de um tempo devastador que instaura a finitude e a morte, rompendo a cadeia da causalidade e toda concepção de uma infinitude do tempo, tal como o conceito de destino preconiza. ${ }^{14}$

CHAVES, E. Myth and politics: notes on the concept of destiny in the "young" Benjamin. Trans/Form/Ação, São Paulo, v. 17, p. 15-30, 1994.

- ABSTRACT: The concept of myth is one of the keys to understand the thought of Walter Benjamin. The aim of this paper is to follow its genesis from the first formulations of the concept of "destiny", as presented in Destiny and character, written in 1919. The present paper is divided in two parts. The first reconstructs Benjamin's arguments, showing them to be within the domain of the theory of rights and their necessary insertion in a "temporality" mode, defined by "repetition"; the second part attempts to demonstrate that Benjamin's positions were closely linked to a political stand: their aim was, in name of an avowed anarchism, to fight against all nationalist "myths" (that brought Germany to war) and the need of "leaders" (Führer) for the people. Examples of this political bias, based on Benjamin's confrontation with Zionism, are presented.

- KEYWORDS: Myth; destiny; character; repetition; anarchism; Zionism.

\section{Referências bibliográficas}

1 ADORNO, T. W. Über Walter Benjamin. Frankfurt am Main: Suhrkamp, 1990.

2 BENJAMIN, W. Briefe. Frankfurt am Main: Suhrkamp, 1978.

3 _. Origem do drama barroco alemão. São Paulo: Brasiliense, 1985.

4 Gesammelte Schriften I. Frankfurt am Main: Suhrkamp, 1991a.

5 _ Gesammelte Schriften II. Frankfurt am Main: Suhrkamp, 1991b.

6 _. Gesammelte Schriften V. Frankfurt am Main: Suhrkamp, 1991c.

7 Gesammelte Schriften VI. Frankfurt am Main: Suhrkamp, 1991d.

8 GAGNEBIN, J. M. Notas sobre as noções de origem e original em Walter Benjamin. 34 Letras, n. 5/6, set. 1989.

9 HEGEL, G. W. Vorlesungen über die Ästhetik. In: Werke III Frankfurt am Main: Suhrkamp, 1986a. v. 15.

14. Assim sendo, nossa interpretação é oposta à de Olgária Matos que, a nosso ver, faz uma valorização excessiva do conceito de destino em Benjamin. Segundo essa intérprete, a partir, supostamente, de Destino e caráter, Benjamin "vai mostrando que ninguém escapa ao seu destino significa que ninguém escapa ao real e que o real é acaso. Ninguém escapa ao destino significa que ninguém escapa ao acaso" (1992, p. 155). Ora, o "herói trágico", "paradoxalmente", através da morte, escapa a o destino. Contudo, a única relação entre destino e acaso na obra de Benjamin, em Origem do drama barroco alemão, se dá no interior da análise do drama barroco como drama do destino com conseqüências bem diversas. Não se trata, enfim, como diz Olgária Matos, de "reconhecer o acaso e utilizá-lo a nosso favor", mas de "saltar para fora do destino mítico". 
10 HEGEL, G. W. Grundlinien der Philosophie des Rechts. In: Werke VII. Frankfurt am Main: Suhrkamp, 1986b.

11 JANZ, R-P. Mythos und moderne bei Walter Benjamin. In: BOHRER, K.-H. (Hrs.). Mythos und moderne. Frankfurt am Main: Suhrkamp, 1983.

12 KAMBAS, C. Walter Benjamin liest Georges Sorel: Réflexions sur la violence. In: Aber ein Sturm weht vom Paradise her. Texte zu Walter Benjamin. Leipzig: Reclam, 1992.

13 LEWY, Z. Über Franz Rosenzweigs Auffassung des Mythos. In: Der Philosoph Franz Rosenzweig (1886-1929). Internationaler Kongress Kassel 1986. Freiburg/München: Verlag Karl Alber, 1988. v. II.

14 LÖWY, M. L'anarchisme messianique de Walter Benjamin. Les Temps Modernes, n. 447, oct. 1983.

15 MATOS, O. Memória e história em Walter Benjamin. In: O direito à memónia. Patrimônio histórico e cidadania. São Paulo: DPH/Secretaria Municipal de Cultura/Prefeitura Municipal de São Paulo, 1992.

16 MENNINGHAUS, W. Romeo und Julia auf dem Dorfe. Eine Interpretation im Anschluss an Walter Benjamin. In: Artistische Schrift. Studien zur Kompositionskunst Gottfried Kellers. Frankfurt am Main: Suhrkamp, 1982.

17 . Schwellenkunde. Walter Benjamins Passagen des Mythos. Frankfurt am Main: Suhrkamp, 1986.

18 ROSENFELD, A. Texto/Contexto II. São Paulo: Perspectiva/EDUSP; Campinas: Editora da UNICAMP, 1993.

19 SCHOLEM, G. As grandes correntes da mística judaica. São Paulo: Perspectiva, 1972.

20 . A Cabala e seu simbolismo. São Paulo: Perspectiva,1988.

21 Walter Benjamin - história de uma amizade. São Paulo: Perspectiva, 1989.

22 TIEDEMANN, R. Études sur la philosophie de Walter Benjamin. Arles: Edictions Actes Sud, 1987. 